\title{
THE PROGNOSTIC VALUE OF NATURAL KILLER CELL INFILTRATION IN RESECTED PULMONARY ADENOCARCINOMA
}

Iwao Takanami, MD

Ken Takeuchi, MD

Masatoshi Giga, MD
Objective: Natural cytotoxicity caused by mediated natural killer cells is believed to play an important role in host-cancer defense mechanisms. Immunohistochemically, we have detected natural killer cells in tissue specimens from patients with pulmonary adenocarcinoma and have assessed their clinical characteristics.

Methods: Using the monoclonal antibody for CD57 specific marker for natural killer cells, we quantified natural killer cell infiltration in 150 patients with pulmonary adenocarcinoma who underwent curative tumor resection to investigate the relationship between natural killer cell counts and clinicopathologic factors and prognosis.

Results: The natural killer cell count was significantly related to the regulation of tumor progression, involving $\mathrm{T}$ classification, $\mathrm{N}$ classification, and stage ( $P=.01$ for $\mathrm{T}$ classification or stage; $P=.02$ for $\mathrm{N}$ classification). A significant difference in the rate of patient survival was detected between those patients whose tumors had either high or low natural killer cell counts in both the overall and stage I groups $(P=.0002$ for the overall group; $P=$ .049 for the stage I group).

Conclusion: These data indicate that natural killer infiltration may contribute to the regulation of tumor progression and that the natural killer cell count can serve as a useful prognostic marker in overall and stage I pulmonary adenocarcinoma. (J Thorac Cardiovasc Surg 2001;121:1058-63)
$T_{\text {iin }}^{\text {h }}$ he incidence of pulmonary adenocarcinoma is increasing globally, and this condition is the most common histologic type in the United States and Japan. ${ }^{1,2}$ However, the behavior of pulmonary adenocarcinomas is not well understood. The results of the treatment of pulmonary adenocarcinomas with surgery, other therapies, or both remain unsatisfactory, and even for those tumors classified as stage I, treatment fails in $30 \%$ of patients with stage I adenocarcinoma. ${ }^{2}$ Therefore, there is a need to identify new biologic markers as prognostic indicators in pulmonary adenocarcinoma.

Tumor-infiltrating lymphocytes of tumors have been considered to be a good prognostic factor in some tumors. ${ }^{3-8}$ Natural killer (NK) cells in tumor-infiltrating lymphocytes exhibit a spontaneous cytotoxic capacity against tumor cells, suggesting that they play a particu-

From the First Department of Surgery, Teikyo University School of Medicine, Tokyo, Japan.

Copyright (c) 2001 by The American Association for Thoracic Surgery

$0022-5223 / 2001 \$ 35.00+0 \quad \mathbf{1 2 / 1 / 1 1 3 0 2 6}$

doi:10.1067/mtc.2001.113026 lar role in the regulation of tumor cell proliferation and tumor surveillance. ${ }^{9}$ Immunohistochemical staining with a monoclonal antigen for surface marker IOT-10 (CD57) provides a sensitive means for the identification of NK cells in paraffin-embedded specimens. ${ }^{10}$

By using the monoclonal antibody for CD57, we therefore investigated how the NK infiltration is related to the regulation of tumor progression and prognosis in a series of 150 cases of curatively resected pulmonary adenocarcinoma.

\section{Methods}

Patients. Tissue specimens from 150 patients who underwent curative pulmonary adenocarcinoma resection at the First Department of Surgery, Teikyo University, between 1989 and 1994 were studied. Patients who died within 1 month after the operation and those who underwent exploratory thoracotomy were excluded from the present study. Patients with a history of another cancer were also excluded.

The lesions of these 150 patients were staged on both the operative and pathologic findings according to the International Union Against Cancer (UICC) TNM classification. ${ }^{11}$ The histologic subtypes of adenocarcinoma were evaluated according to 1997 World Health Organization criteria. 
Table I. Patient characteristics

\begin{tabular}{lc}
\hline & No. of patients \\
\hline Total & 150 \\
Male & 83 \\
Female & 67 \\
Stage & \\
IA & 47 \\
IB & 35 \\
IIA & 6 \\
IIB & 15 \\
IIIA & 47 \\
Subtype & \\
Acinar adenocarcinoma & 77 \\
Papillary adenocarcinoma & 40 \\
Bronchoalveolar adenocarcinoma & 13 \\
Solid carcinoma with mucus formation & 20 \\
Mean age, y (range) & $61(30-81)$ \\
\hline
\end{tabular}

The pertinent data for the patients are summarized in Table I. Patients for whom radical operations had been preoperatively planned by means of either lobectomy or pneumonectomy with a hilar and mediastinal lymph node dissection were considered to have manifested operative indications. None of the patients received neoadjuvant or adjuvant therapies. Postoperatively, all patients were followed up for 5 to 10 years, and their outcomes were known.

Immunologic staining. Each resected tissue specimen was fixed in formalin, embedded in paraffin, and cut into $3-\mu \mathrm{m}$ serial sections. Then by means of the monoclonal antibody for IOT-10 (CD57, NCI immunoglobulin M; Immunotech SA, Division of Beckman Coulter, Inc, Fullerton, Calif), the sections were subjected to hematoxylin and eosin staining and immunohistologic staining for CD57. Monoclonal antibody CD57 reacts with cell surface polypeptides present in mononuclear cells with NK activity. ${ }^{12}$ Immunohistologic staining for CD57 was based on the avidin-biotin-peroxidase complex method and was performed by using a Vestatin Kit (Vector Laboratories, Inc, Burlingame, Calif). Negative control sections were treated with nonimmunized mouse immunoglobulin $\mathrm{G}$ as the primary antibody.

Determination of NK cells. Immunologic CD57 staining was evaluated by means of light microscopy by 2 independent observers (K.T. and M.K.) who were unaware of the patients' cancer history or disease stage. The total number of NK cells was counted in 25 intratumoral areas containing cancerous tissue at a magnification of 200× (area of field, $0.173 \mathrm{~mm}^{3}$ ), according to the method of Coca and associates. ${ }^{13}$ The number of NK cells was determined from the average of the counts taken by the 2 observers.

Statistical analysis. The mean NK count was chosen as the cutoff point to divide the patients into 2 groups, and the relation between groups split by means of mean NK cell counts and clinicopathologic factors was examined by the $\chi^{2}$ test with the Fisher correlation. The survival was then compared between the groups with high and low NK cell numbers, and the survival was calculated by means of the Kaplan-Meier
Table II. Relationship between NK cell counts and various clinicopathologic factors in patients with pulmonary adenocarcinoma

\begin{tabular}{|c|c|c|c|}
\hline \multirow[b]{2}{*}{ Variable } & \multicolumn{2}{|c|}{ NK cell numbers } & \multirow[b]{2}{*}{$\mathrm{P}$ value } \\
\hline & $\begin{array}{c}\text { Low }(\leq 32) \\
n=97\end{array}$ & $\begin{array}{c}H i g h(>32), \\
\quad n=53\end{array}$ & \\
\hline \multicolumn{4}{|l|}{ Age (y) } \\
\hline$\leq 65$ & 59 & 29 & \\
\hline$>65$ & 38 & 24 & .8 \\
\hline \multicolumn{4}{|l|}{ Sex } \\
\hline Male & 55 & 28 & \\
\hline Female & 42 & 25 & .8 \\
\hline \multicolumn{4}{|l|}{$\mathrm{T}$ factor } \\
\hline $\mathrm{T} 1$ & 29 & 28 & \\
\hline $\mathrm{T} 2$ & 56 & 23 & .01 \\
\hline T3 & 12 & 2 & \\
\hline \multicolumn{4}{|l|}{$\mathrm{N}$ factor } \\
\hline No & 50 & 39 & \\
\hline N1 & 9 & 5 & .02 \\
\hline $\mathrm{N} 2$ & 38 & 9 & \\
\hline \multicolumn{4}{|l|}{ Stage } \\
\hline IA & 23 & 24 & \\
\hline IB & 21 & 14 & \\
\hline IIA & 3 & 3 & .01 \\
\hline IIB & 12 & 3 & \\
\hline IIIA & 38 & 9 & \\
\hline \multicolumn{4}{|l|}{ Subtype } \\
\hline Acinar & 52 & 25 & \\
\hline Papillary & 22 & 18 & \\
\hline Bronchoalveolar & 10 & 3 & .9 \\
\hline Solid & 13 & 7 & \\
\hline
\end{tabular}

method and compared with the results of the log-rank test. Each prognostic factor was evaluated with regard to survival in a multivariate analysis by using the Cox proportional hazards regression model. Computer calculations were performed with the StatView statistical package (Abacus Concepts, Inc, Berkeley, Calif) and a Macintosh System G3 computer (Apple Computer, Cupertino, Calif).

\section{Results}

Relationship between NK counts and clinicopathologic parameters. In the current study the majority of $\mathrm{CD} 57^{+}$cells were found in the intratumoral stroma. The NK cells usually were distributed near the surface of the tumor (Fig 1, A-D). The NK cells ranged in number from 3 to 257 , with a mean of $32.0 \pm 36.4$, and therefore we classified the patients into 2 groups: the high NK cell count group $(n=53)$, for which NK cells numbered greater than 32 , and the low NK cell count group $(n=97)$, for which NK cells numbered 32 or less. Table II shows the clinicopathologic parameters for these 2 groups. There were no significant intergroup differences regarding age, sex, or subtype of pul- 

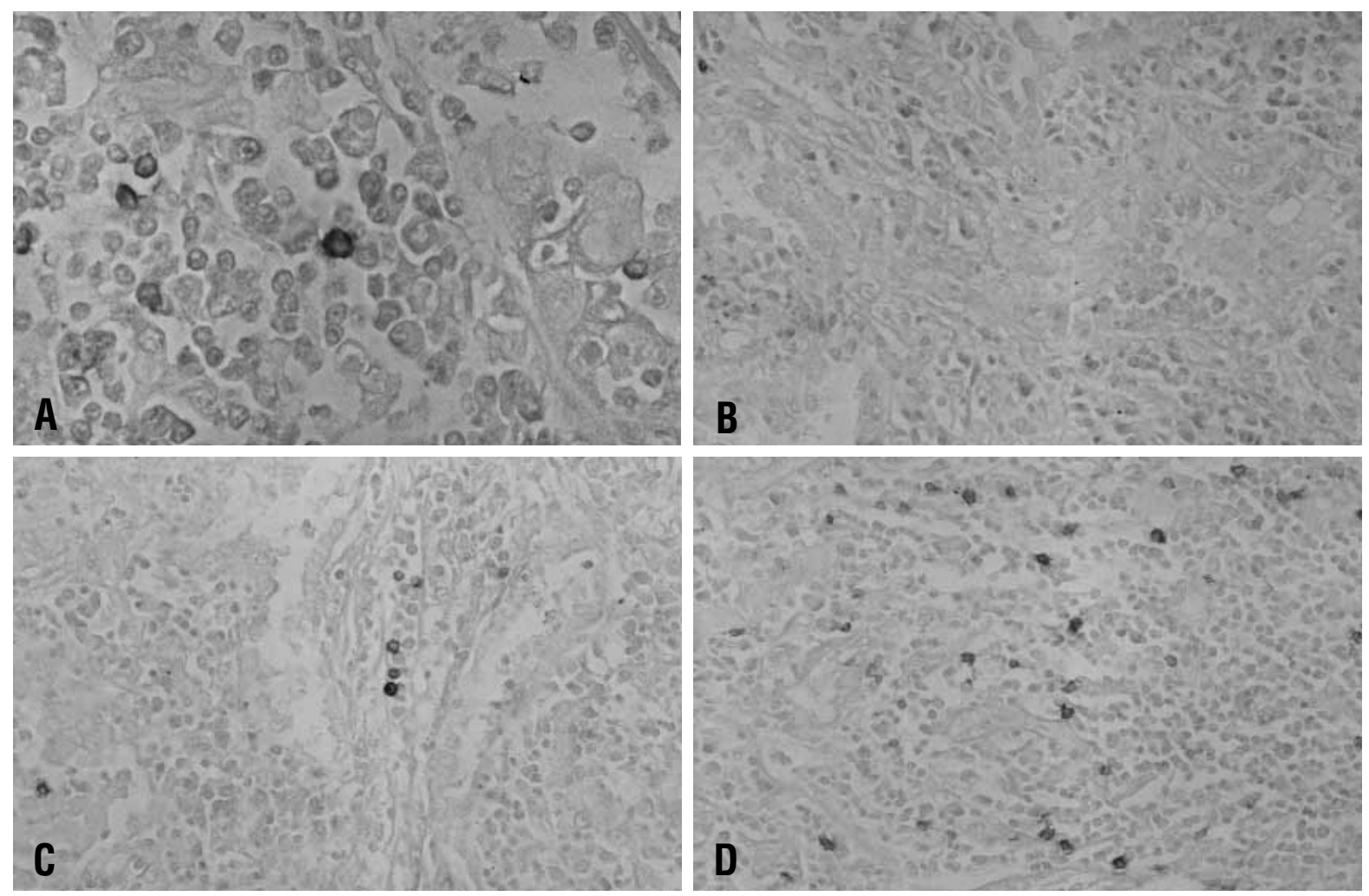

Fig 1. A and $\mathbf{B}$ show immunohistochemical staining of pulmonary adenocarcinoma with IOT-10 (CD57) monoclonal antibody. Positive cells are identified in the stroma of the tumor (arrowhead). Photographs of pulmonary adenocarcinoma show a negative control, a low level, and a high level of NK-cell infiltration. (A: original magnification $200 \times$; B, C, and D: original magnification $80 \times$.)

monary adenocarcinoma. As can be seen, NK cells were significantly related to the $\mathrm{T}$ classification, $\mathrm{N}$ classification, and stage $(P=.01$ for $\mathrm{T}$ classification or stage; $P=.02$ for $\mathrm{N}$ classification).

Relations between NK counts and survival. Of the 150 tumors staged with TNM classification, 82 were stage I (stage IA and stage IB), 21 were stage II (stage IIA and stage IIB), and 47 were stage III (stage IIIA). Patients were classified into 2 groups on the basis of intratumoral NK cells at the mean cutoff point. The survival was then compared between the high NK cell count group and the low NK cell count group in overall, stage I, stage II, and stage III disease. Figs 2 and 3 show the difference in survivals between the high NK cell count group and the low NK cell count group in the overall and stage I groups $(P=.0002$ for the overall group; $P=.049$ for the stage I group). Although the 5-year survival in the high NK cell count group is better than that in the low NK cell count group in the stage II and stage III groups, there is not a difference in survival between the 2 groups (Figs 4 and 5).
Univariate and multivariate analyses. NK cell infiltration, $\mathrm{T}$ classification, and $\mathrm{N}$ classification were analyzed by means of the Cox proportional hazards regression model (Table III). NK cell infiltration is a prognostic factor in univariate analysis. Although $\mathrm{T}$ classification and $\mathrm{N}$ classification were independent prognostic factors, NK cell infiltration was not an independent prognostic factor in multivariate analysis.

\section{Discussion}

There have been some studies detailing the correlation between prognosis and local immune cell infiltration, and high tumor infiltrating lymphocytes were associated with improved prognosis for patients with lung cancer. ${ }^{5,6}$ Previous studies also suggest a beneficial effect of an enhanced immune cell infiltrate in lung cancer. One study has immunohistochemically identified that CD3 (pan-T cell) in excess in lung tumors is associated with a good prognosis. ${ }^{14}$ Another study described the prognostic benefit of tumor-infiltrating CD45RO (memory T cell) in lung cancer. ${ }^{15}$ In contrast to $\mathrm{CD} 3$ and $\mathrm{CD} 45 \mathrm{RO}$, the number of intratumoral infil- 


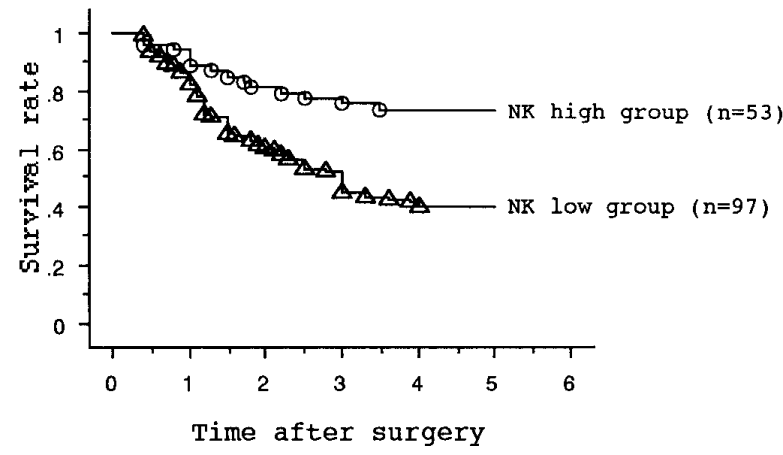

Fig 2. Overall survival curves of the patients with pulmonary adenocarcinoma on the basis of NK cell infiltration. A significant difference was seen between the 2 groups $(P=.0002)$.

trations by CD8 (T suppressor-cytotoxic cell) had no statistically significant effect on patient survival. ${ }^{16}$ Most of the infiltrating lymphocytes consist of $\mathrm{T}$ cells, and NK cells constitute a small portion of the tumorinfiltrating lymphocytes, which create spontaneous cell-mediated cytotoxicity in patients with cancer. ${ }^{9}$ It was reported that there was a discrepancy between the degree of lymphocytic infiltration and the number of infiltrating NK cells. ${ }^{17}$ The number of NK cells contacting neoplastic cells plays an important role in host anticancer defense mechanisms. ${ }^{9}$ To our knowledge, this is the first report to analyze the prognostic influence of NK cells in pulmonary adenocarcinoma and the possible associations between this parameter and other clinical factors.

NK cells are predominantly large granular lymphocytes, the majority of which express CD16 and CD56 cell surface antigens. CD57 is detected on only $30 \%$ to $70 \%$ of NK cells and T cells, ${ }^{9}$ and cells stained with anti-CD57 antibody may have to be called $\mathrm{CD} 57^{+}$cells; CD57 has been widely used as an NK cell marker. ${ }^{10,12,13,17}$ We have chosen the monoclonal antibody IOT-10 (CD57) for identification of NK cells because it was reported to constantly and accurately immunostain NK cells on paraffin-embedded specimens. ${ }^{12}$ In our study IOT- $10^{+}$NK cells were present in all specimens of pulmonary adenocarcinoma studied, and the majority of them were found in small numbers dispersed among tumor cells near the surface of the tumor.

In this study the total number of NK cells was counted in 25 intratumoral areas, and the patients were classified into 2 groups according to the cutoff point of mean NK cells per 25 fields at a high magnification. Previous reports established a value of 25 NK cells per 25 fields as the cutoff point, ${ }^{13,17}$ although the reason for

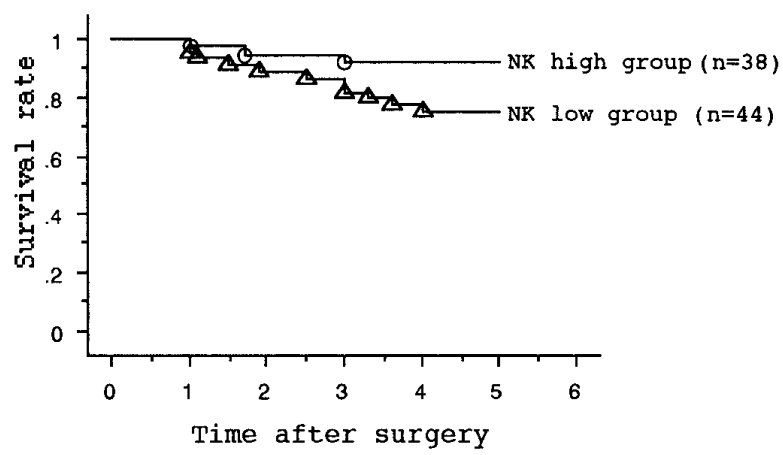

Fig 3. Survival curves of the patients with stage I pulmonary adenocarcinoma on the basis of NK classification. A significant difference was seen between the 2 groups $(P=.049)$.

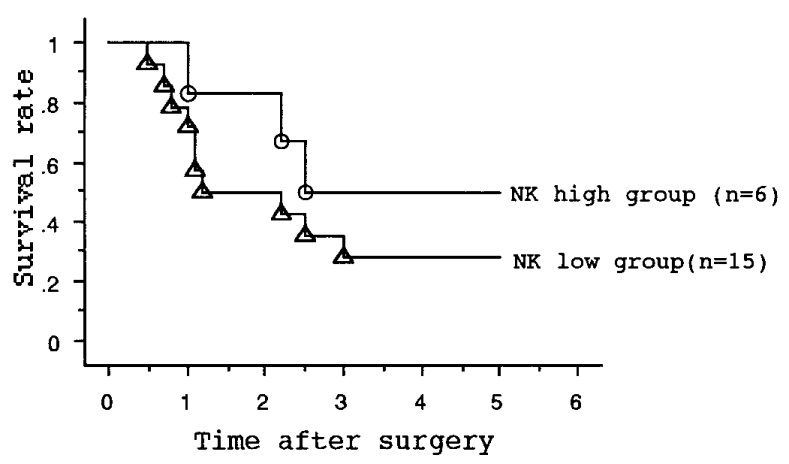

Fig 4. Survival curves of the patients with stage II pulmonary adenocarcinoma on the basis of NK classification. A significant difference was not seen between the 2 groups $(P=.3)$.

this is uncertain. The mean number has been widely used as the cutoff point to divide the patients into 2 groups. The results of this study showed that high levels of NK cells were found in 35\% (53/150) of our patients with pulmonary adenocarcinoma. A histogram plot of the NK numbers in patients showed that some tumors had very high numbers of positive-stained cells (data not shown). We found that the value of the NK cell counts was associated with $\mathrm{T}$ classification, $\mathrm{N}$ classification, and stage in clinicopathologic factors. Our results support previous reports in which NK cell infiltration was found to correlate with the clinical stage in gastric carcinoma. ${ }^{17}$

The TNM staging is an important predictor of survival. The 5-year survivals were $82 \%$ in stage I, $38 \%$ in stage II, and $10 \%$ in stage III disease in this study. Surgical adjuvant chemotherapy has little effect on the treatment of patients with non-small cell lung carcino- 


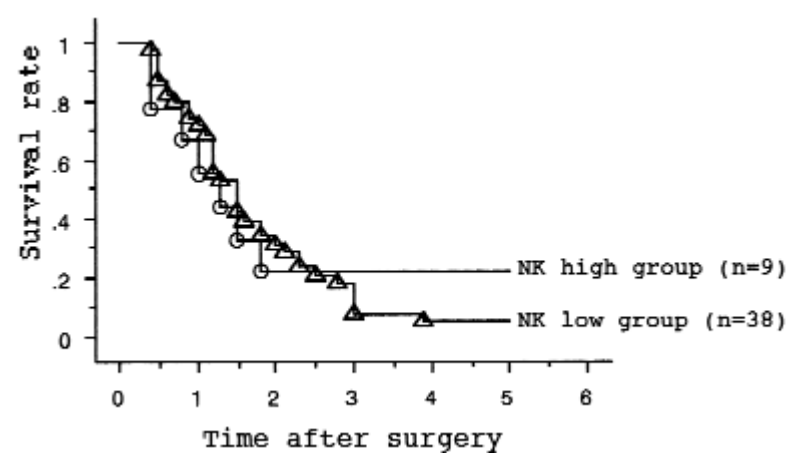

Fig 5. Survival curves of the patients with stage III pulmonary adenocarcinoma on the basis of NK classification. A significant difference was not seen between the 2 groups $(P=.8)$.

ma. Although there were many patients with lymph node metastasis, we did not use neoadjuvant or adjuvant therapies in the current study. T classification, $\mathrm{N}$ classification, and stage were identified as important prognostic factors in this series of patients with pulmonary adenocarcinoma. High NK counts were associated with an improved prognosis with colorectal carcinoma and gastric carcinoma. ${ }^{13,17}$ In the current study we found a positive correlation between NK cell infiltration and the surgical outcome in the groups of patients with all types of pulmonary adenocarcinoma. When we compared patients in each stage, we found a positive correlation between NK cell infiltration and surgical outcome in stage I cancer but not a positive correlation in stage II and stage III disease. NK cells are thought to be one of the main effectors responsible for the antitumor early defense and also to have a strong influence on the subsequent antitumor immune response. ${ }^{18}$ In the current study a possible immune response by NK cells against the tumor seems to be relevant in a relatively early stage of pulmonary adenocarcinoma. As can be seen in Table III, T classification and $\mathrm{N}$ classification were correlated with surgical outcome by means of univariate analysis. The Cox multivariate proportional analysis was performed by means of T classification, $\mathrm{N}$ classification, and NK cell infiltration. Although NK cells were a prognostic factor in the univariate analysis, NK cell infiltration was not picked up as an independent prognostic factor in the multivariate analysis. Perhaps this is because NK cell infiltration correlates with $\mathrm{T}$ classification and $\mathrm{N}$ classification. Although NK cells are reported to exhibit a spontaneous cytotoxic capacity against tumors cells, this had an influence in only stage I disease in our
Table III. Univariate and multivariate analyses of clinical factors in pulmonary adenocarcinoma

\begin{tabular}{lccr}
\hline Factors & $\begin{array}{c}\text { Univariate analysis } \\
(\mathrm{P} \text { value })\end{array}$ & \multicolumn{2}{c}{ Multivariate analysis } \\
\cline { 3 - 4 } T classification & $<.0001$ & $\chi^{2}$ & $\mathrm{P}$ value \\
N classification & $<.0001$ & 11.980 & .0025 \\
NK cell & .0002 & 29.327 & $<.0001$ \\
& & 2.417 & .1201 \\
\hline
\end{tabular}

study. The lack of statistical significance of NK activity in multivariate analysis may support the effect of NK activity.

In conclusion, we found, in this series of patients with pulmonary adenocarcinoma, that NK counts play an important role in the regulation of tumor progression and that NK counts can be a useful marker in terms of survival of patients with stage I cancer. Further studies are required to determine the adjuvant use of immune biologic response modifiers in patients with low levels of NK cell infiltration, and an increasing understanding of this field may allow for the future development of anticancer therapies.

Received for publication July 28, 2000; revisions requested Sept 13, 2000; revisions received Oct 5, 2000; accepted for publication Oct 11, 2000.

Address for reprints: Iwao Takanami, First Department of Surgery, Teikyo University School of Medicine, 11-1 Kaga 2Chome, Itabashi-Ku, Tokyo 173, Japan (E-mail: takanami@med.teikyo-u.ac.jp).

\section{REFERENCES}

1. Parker SL, Tong T, Bolden S, Wingo PA. Cancer statistics 1997. Ca Cancer J Clin 1997;47:5-27.

2. Naruke T, Goya T, Tsuchiya R, Suematsu K. Prognosis and survival in resected lung carcinoma based on the new internal staging system. J Thorac Cardiovasc Surg 1998;96:440-7.

3. Jass JR. Lymphocytic infiltrating and survival in rectal cancer. J Clin Pathol 1986;39:585-9.

4. Okamura T, Kodama Y, Komegawa T, Sano C, Kumashira R, Inokuchi K. Gastric carcinoma with lymphoid stroma: correlation to reactive hyperplasia in regional lymph nodes and prognosis. Jpn J Surg 1983;13:177-83.

5. Aaltomann S, Lipponen P, Eskelinen M, Kosma VM, Marin S, Alhava E, et al. Lymphocyte infiltrates as a prognostic variable in female breast cancer. Eur J Cancer 1992;28A:859-64.

6. Ikeguchi M, Saito H, Katano K, Tsujitani S, Maeta M, Kaibara N. Correlation between the lymphocytic infiltration of tumors and the proliferative activity of cancer cells from surgically treated esophageal carcinoma. Oncology 1997;54:311-7.

7. Lee T-K, Horner RD, Silvermannn JI, Chen Y-H, Jenny C, Scarantino CW. Morphometric and morphologic evaluation in stage III non-small cell lung cancers: prognostic significance of quantitative assessment of infiltrating lymphoid cells. Cancer 1989;63:309-16. 
8. Lipford EH, Sears DL, Eggleston JC, Moore GW, Lillemoe KD, Baker RR. Prognostic factors in surgical resected limited-stage, non-small cell carcinoma of the lung. Am J Surg Pathol 1984;8:357-65

9. Brittenden J, Heys SD, Ros J, Eremin O. Natural killer cells and cancer. Cancer 1996;77:1226-43.

10. Vaquero J, Coca S, Mogallon R, Ponton P, Martinez R. Immunohistochemical study of natural killer cells in tumor-infiltrating lymphocytes of primary intracranial germinomas. J Neurosurg 1990;72:619-25.

11. Sobin $\mathrm{LH}$, Wittekind $\mathrm{CH}$, editors. International Union Against Cancer TNM classification of malignant tumors. 5th ed. New York: John Wiley; 1997.

12. Vincent M, Thiery JP. A cell surface marker for neural crest and placodal cells: further evaluation in peripheral and central nervous system. Dev Biol 1984;103:468-81.

13. Coca S, Perez-Piqueras J, Martinez D, Colmenarejo A, Saez MA, Vallejo $\mathrm{C}$, et al. The prognostic significance of intratumoral nat- ural killer cells in patients with colorectal carcinoma. Cancer 1997;79:2320-8

14. Johnson SK, Kerr KM, Capman AD, Kennedy MM, King G, Cockburn JS, et al. Immune cell infiltrates and prognosis in primary carcinoma of the lung. Lung Cancer 2000;27:27-35.

15. Tosi P, Sforza V, Anntopietro R, Lio R, Gotti G, Paladini P, et al. Bronchiolo-alveolar carcinoma: an analysis of survival predictors. Eur J Cancer 1992;28A:1365-70.

16. Mori M, Ohtani H, Naito Y, Sagawa M, Sato M, Fujimura S, et al. Infiltration of CD8+ T cells in non-small cell lung cancer is associated with dedifferentiation of cancer cells, but not with prognosis. Tohoku J Exp Med 2000;191:113-8.

17. Ishigami S, Natsugoe S, Tokuda K, Nakajo A, Che X, Iwashige $\mathrm{H}$, et al. Prognostic value of intratumoral natural killer cells in gastric carcinoma. Cancer 2000;88:577-83.

18. Kurosawa S, Harada M, Matsuzaki G, Shinomiya Y, Terao H, Kobayashi N, et al. Early-appearing tumor-infiltrating natural killer cells play a crucial role in the generation of anti-tumor $\mathrm{T}$ lymphocytes. Immunology 1995;85:338-46.

\section{Notice of correction}

In the February 2001 issue of the Journal, in the article by Suehiro and associates titled "Direct Coronary Artery Perfusion From the Left Ventricle" (2001;121:307-15), an error was made. The wrong copy of Fig 7 was published. The correct version of Fig 7 is published below, and the correct version of the article is available online at www.mosby.com/jtcvs.

A
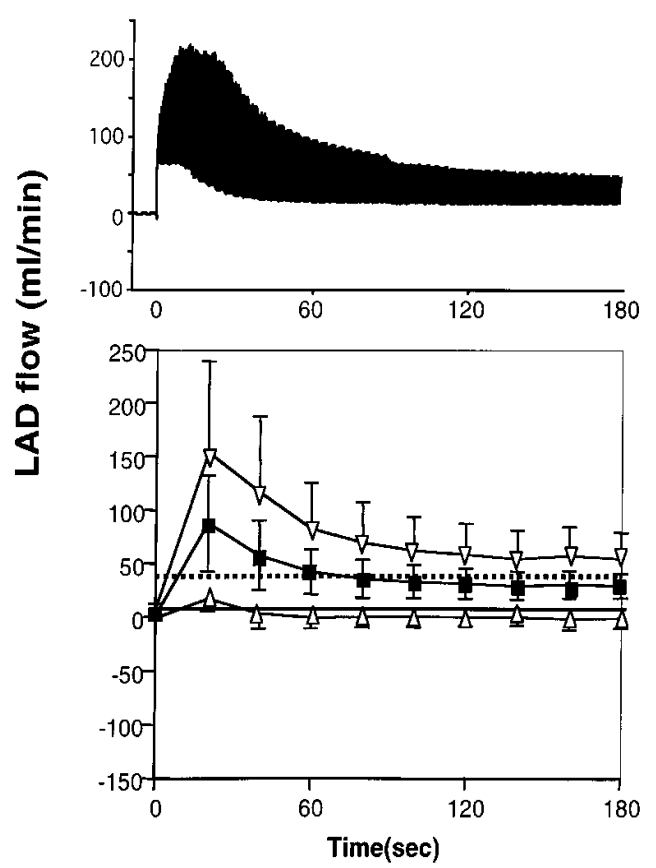

C $\nabla$ Maximum LAD flow $\triangle$ Minimum LAD flow
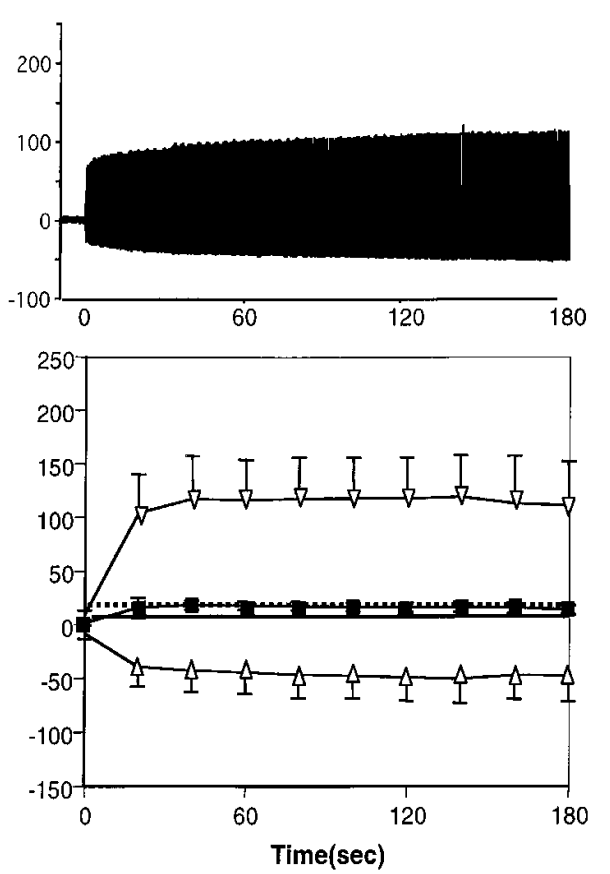

Mean LAD flow

Fig 7. Representative tracings of reactive hyperemic flow and mean LAD flow after release of a 2-minute LAD occlusion before (A and $\mathbf{C}$, respectively) and after (B and D, respectively) establishing an LV-LAD conduit with $\mathrm{P}_{\text {Starling }}=0$. See Fig 3 for abbreviations. 